\title{
Morphological Analysis of Laser Exposed Phenolic-based Nanocomposites
}

\author{
S. Young and H. Aglan \\ College of Engineering, Tuskegee University, Tuskegee, AL 36088 USA
}

Polymers are subjected to heat, radiation, moisture and other conditions that may promote accelerated degradation in a broad range of industrial and scientific applications. Studies on the effect that severe environmental conditions have on polymers are critical to understand how to prevent or impede their degradation. High-energy lasers that effectively simulate fires' heat were employed to study the degradation mechanisms of polymeric systems [1-3] and the effect evaluated. The study concentrated on the mechanical properties and fracture surface morphology of nano-reinforced structural epoxy systems after pulse-laser irradiation. The type of nano-reinforcement used appears to have the largest effect on the degradation mechanisms of the tested materials when exposed to laser pulse-laser irradiation [4].

Nanoparticles, either alumina nanofibers (ANF) or MWCNT were incorporated into the resole phenolic resin at a $0.15 \%$ loading (by weight). The samples were then exposed to pulsed laser (Nd:YAG) for 90 seconds at the notch tip. Optical micrographs were captured with a Wild Heerbrugg M3Z microscope. After flexural testing, the fracture surfaces were cut from the sample and sputtered coated with Au-Pd alloy. The specimens were examined using a Hitachi S-2150 SEM. These images were then compiled into composite fractographs.

Optical micrographs with the top surface morphology of the laser-exposed zones are shown in Figure 1 (projection of the $x-y$ plane). After 90 seconds of laser exposure, the phenolic systems exhibit cracks and charring, characterized by iridescent features (Fig. 1a-1c). Charring observed in the MWCNT/phenolic system is more dominant compared to the neat and ANF/phenolic systems. Individual fracture surfaces (projections of the $y-z$ plane) of the phenolic systems were imaged with a SEM and assembled into a mosaic. Individual images were captured at 80x magnification. Fractographs for the (a) neat phenolic, (b) $0.15 \mathrm{wt} \% \mathrm{ANF} / \mathrm{phenolic}$, and (c) $0.15 \mathrm{wt} \% \mathrm{MWCNT} / \mathrm{phenolic}$ specimens are shown in Figure 2.

Microcracks and granular-like morphological features are observed in all specimen types. The neat phenolic and $0.15 \mathrm{wt} \% \mathrm{ANF} / \mathrm{phenolic} \mathrm{systems} \mathrm{are} \mathrm{characterized} \mathrm{by} \mathrm{cracks} \mathrm{and} \mathrm{granular-like} \mathrm{structures}$ on the fracture surface. The dominant features of the $0.15 \mathrm{wt} \% \mathrm{MWCNT} / \mathrm{phenolic}$ system are the more intense microcracks, compared to the neat phenolic and $0.15 \mathrm{wt} \% \mathrm{ANF} / \mathrm{phenolic}$. It is rationalized that the enhanced microcracks result from the highly conductive MWCNTs' ability to dissipate more localized heat in the specimen. The granular-like structures appear to be larger in the $0.15 \mathrm{wt} \%$ MWCNT/ phenolic specimen than those present in the neat phenolic and $0.15 \mathrm{wt} \% \mathrm{ANF} / \mathrm{phenolic}$. The fractographs were used to estimate the laser-affected depth of the specimens. The average damage zone depths for the neat phenolic, $0.15 \mathrm{wt} \%$ ANF/phenolic, and $0.15 \mathrm{wt} \% \mathrm{MWCNT} /$ phenolic specimens are $2.2 \mathrm{~mm}, 2.1 \mathrm{~mm}$, and $1.4 \mathrm{~mm}$, respectively.

Top surface and fracture surface morphologies were performed by optical and SEM on laser exposed phenolic resin systems. The results show that the neat phenolic and $0.15 \mathrm{wt} \% \mathrm{ANF} /$ phenolic dissipated the laser energy throughout the material, creating a large damage area with severe cracking through the thickness of the material. The $0.15 \mathrm{wt} \% \mathrm{MWCNT} /$ phenolic system exhibited more localized damage due to laser exposure. Since MWCNTs are highly conductive by nature, their incorporation into the phenolic resin yielded more favorable morphological properties upon laser exposure, compared to the neat and ANF/phenolic systems. 


\section{References}

1. D. Price, G. Milnes, C. Lukas, and T. Hull, Int. J. Mass Spectrom. Ion Phys. 60 (1984) 225-235.

2. E. Bormashenko, R. Pogreb, A, Sheshnev, E. Shulzinger, Y. Bormashenko, S. Sutovski, and A. Katzir, Polym. Degrad. Stability 72 (2001) 125-131.

3. B. Marosfoi, G. Marosi, A. Szabo, B. Vajna, and A. Szep, Polym. Degrad. Stability 92 (2007) 22312238.

4. M. Calhoun, A. Kumar, and H. Aglan, J. Appl. Polym. Sci. 113 (2009) 3156-3164.

5. Supported by the US Department of Energy Grant DE-FG52-05NA27039
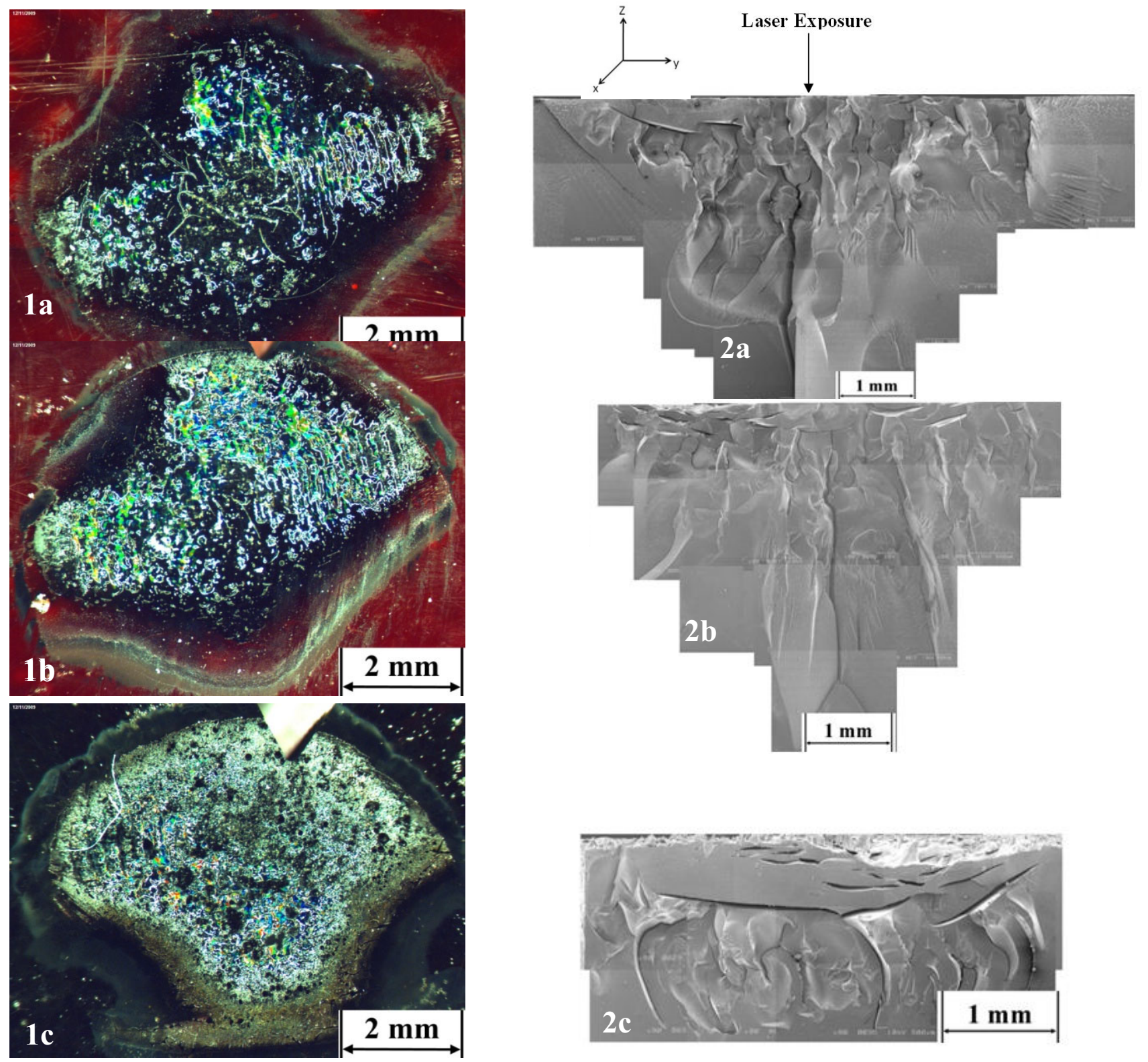

Fig. 1. Top view of the laser affected area in the (a) neat phenolic, (b) $0.15 \%$ ANF/phenolic, and (c) $0.15 \% \mathrm{MWCNT} /$ phenolic after 90 seconds of exposure.

Fig. 2. Composite fractographs $(80 \mathrm{x})$ of phenolic specimens exposed to laser for 90 second, (a) neat phenolic, (b) $0.15 \mathrm{wt} \% \mathrm{ANF} /$ phenolic, and (c) $0.15 \mathrm{wt} \% \mathrm{MWCNT} / \mathrm{phenolic}$. 